\title{
Problematização das relações entre História e Literatura na historiografia portuguesa actual: alguns exemplos
}

\author{
Problematization of the Relationship between History and Literature in \\ the Current Portuguese Historiography: Some Examples
}

\author{
Nuno Bessa Moreira \\ knunoclio@gmail.com \\ Doutor \\ Universidade do Porto \\ Via Panorâmica Edgar Cardoso \\ 4150-564 - Porto \\ Portugal
}

\begin{abstract}
Resumo
Este artigo trata o tema da narrativa historiográfica, relacionando-o com a literatura, desde os anos 1980, e na virada do século XX para o XXI, em Portugal - assunto escassamente abordado. Situamo-nos numa História da Historiografia comparativa, salvaguardando um enquadramento sintético da evolução desta área durante o século $X X$, considerando-se uma perspectiva internacional da História Narrativa. Serão analisados três textos específicos, da autoria de Fátima Bonifácio, Rui Bebiano e Luís Adão da Fonseca. Projetando conclusões, defende-se que a História Narrativa não alberga uma realidade una e homogénea. Enquanto Maria de Fátima Bonifácio parece pugnar pelo retorno da velha História, Rui Bebiano entende-a como poética, sem abdicar do rigor na pesquisa de fontes. Luís Adão da Fonseca defende a manutenção da história científica, mas considera que esta deve se conjugar com um estilo literário.
\end{abstract}

\section{Palavras-chave}

História narrativa; Pós-modernismo; Historiografia portuguesa.

\begin{abstract}
This article concerns the theme of the historiographical narrative, relating it with literature, since the 1980 s and in the turn of the $19^{\text {th }}$ to the $20^{\text {th }}$ century in Portugal - a barely addressed theme. It focuses on comparative History of Historiography and provides a synthetic framing of the evolution of this area during the 20th century, considering an international perspective of Narrative History. Three specific texts, written by Fatima Bonifácio, Rui Bebiano and Luís Adão da Fonseca, will be analyzed. The article concludes that Narrative History does not harbor a single and homogeneous reality. While Maria de Fátima Bonifacio seems to strive for narrative history through the return of the old history, Rui Bebiano understands it as poetics, without sacrificing the rigor of source research. Luís Adão da Fonseca, on his turn, defends scientific history while considering that it should be combined with a literary style
\end{abstract}

\section{Keywords}

Narrative history; Postmodernism; Portuguese historiography. 
A história da historiografia vive na actualidade um momento de particular efervescência no Brasil, sendo que em Portugal se encontra em vias de desenvolvimento. A aferição circunstanciada destas afirmações e da comparação que delas pode resultar não cabem nesta pesquisa (MOREIRA 2012, p. 17-47). Ainda assim, um exercício deste tipo pode subordinar-se a critérios diversos que são passíveis de incluir o rastreio de autores e obras (artigos em publicações periódicas, participação em empreendimentos de natureza coletiva, monografias, dissertações acadêmicas de mestrado e doutoramento), consignando, igualmente, em trabalhos futuros, a inventariação de universidades e faculdades nas quais a disciplina de História da Historiografia seja lecionada. Importa igualmente enumerar centros e linhas de investigação, sublinhando a existência ou não de agremiações científicas, colóquios e congressos especificamente dedicados a esses assuntos.

João Paulo Avelãs fez um balanço bastante desenvolvido da Historiografia Portuguesa desde finais do século XIX até hoje. A acuidade e relevância das suas palavras reclamam que as retomemos:

Por seu lado, a historiografia e, de forma mais sincrética, a "memória
histórica", terão evoluído de uma fase de abertura a diversas correntes
intelectuais mas na qual se verificava o predomínio das concepções da
"escola metódica", do historicismo romântico e do positivismo (até ao
início da Primeira Grande Guerra) para uma etapa de acrescido pluralismo
científico-cultural e de reforçado envolvimento político-ideológico (1914-
1930). Seguiram-se a etapa de construção e imposição coerciva do
"historicismo neo-metódico" (1930-1974); o período do regresso a uma
lógica de pluralismo científico-ideológico e da internacionalização - da
comunidade de historiadores e dos públicos -, baseada no predomínio da
"nova história" até hoje (NUNES 2013, p. 59).

Tal como o historiador citado, utilizaremos, neste artigo, a expressão Historiografia Portuguesa para designar historiadores nascidos em Portugal, sem qualquer intuito nacionalista.

Nesta ocasião, interessa sublinhar o pioneirismo de Vitorino Magalhães Godinho (GODINHO 1946; 1971) e da geração à qual pertenceu, a de 1939-1945, na qual se destacou também o seu aluno Joaquim Barradas de Carvalho, que esteve exilado no Brasil e era, pela sua ideologia marxista, um firme opositor do Estado Novo. Tal oposição foi prodigalizada pelo mestre referido, ainda que Magalhães Godinho não tenha seguido, em nosso entender, a mesma ideologia, aproximando-se de uma matriz socialista. A. H. de Oliveira Marques também teve que partir para o exilio, primeiro para a Alemanha, e depois para os Estados Unidos da América. Estes cultores de Clio lançaram as bases da História da Historiografia em novos moldes, neomodernos, assentes na problematização historiográfica e já não centrados na historiografia neometódica, conjugando o rigor científico com um empenhamento cívico inquestionável.

$\mathrm{Na}$ mesma linha, compaginando-a com uma abordagem inovadora da História Política, Armando Carvalho Homem desenvolve, desde os anos 80, uma obra muito importante em qualidade e extensão no âmbito da História da 
Historiografia, dedicando-se ao estudo do percurso de diversos historiadores, como, entre outros, Gama Barros, António Cruz, Oliveira Marques (HOMEM 2008, p. 393-398), Luís Ferrand de Almeida e José Sebastião da Silva Dias. Armando Carvalho Homem tem se dedicado, de modo pioneiro, em diversas ocasiões, à história da Faculdade de Letras do Porto, onde rege e lecciona actualmente, entre outras, as cadeiras de História da Historiografia e Historiografia Portuguesa, sendo esta última uma novidade nas Universidades Portuguesas, que passou a existir em 2007.

Por seu turno, Oliveira Marques publicou em 1988 os Ensaios de Historiografia Portuguesa, onde reafirmou a matriz neomoderna que Godinho tanto cultivou, unindo a crítica de fontes à problematização historiográfica (MARQUES 1988). Nesse mesmo ano, José Mattoso deu à estampa a Escrita da História, com enfoque bem diverso, essencialmente teórico, centrado na temática que o título indicia e nas questões relacionadas com o discurso historiográfico, indagando acerca de assuntos caros à pós-modernidade e o Linguistic Turn. O foco da Escrita da História de José Mattoso é parcialmente outro, provavelmente mais especulativo e teórico-reflexivo, ainda que este historiador convoque a realidade exterior ao cultor de Clio e a verdade histórica como características indispensáveis ao trabalho historiográfico, que cumpre obrigatoriamente três etapas. Na primeira, os historiadores selecionam e organizam as marcas, os vestígios e os traços do passado, patentes mormente em fontes de variada natureza. Em seguida, os estudiosos constroem representações mentais interiores acerca da realidade histórica, mas partem sempre desta. As categorias que materializam são fruto de aturada contemplação; todavia, esta se nutre da observação das "coisas", não a dispensando, ainda que esta seja maioritariamente indirecta e dificilmente penetre o "âmago" dessa realidade. Num terceiro momento, ocorre a escrita da história, que não renega a necessidade de objectivação daquilo a que se refere, nem ludibria a importância de um estilo que salvaguarde uma indeclinável dimensão estética, sem que esta seja autossuficiente ou demande uma atenção exclusiva. No entanto, no trabalho de José Mattoso, a intuição, devidamente informada e fundamentada, parece possuir um valor mais primacial do que na obra de Oliveira Marques.

Em A escrita da História, os excessos de academismo, enciclopedismo e retórica são verberados. Contudo, o historiador salvaguarda a necessidade de utilização moderada destes requisitos, de forma a concretizar um encontro, tão impossível quanto desejado, entre a ciência e a arte: "[...] neste impossível encontro entre a ciência e a arte [...], para denunciar os vícios de certas escritas históricas deturpadas pelo academismo, o enciclopedismo ou a retórica [...]" (MATTOSO 2002, p. 20-21).

A obra de José Mattoso obedece a uma estrutura que abarca os seguintes tópicos de análise: a escrita de História, o ensino, os materiais e os temas. Mattoso indaga: que história ensinar? As respostas que ensaia não são definitivas e comportam margem considerável de incerteza, apontando para a compaginação do rigor científico com uma divulgação atractiva e necessária.

Em 1996 foi publicada a primeira (e única até o momento) História da História em Portugal, obra em cuja introdução os seus autores Luís Reis Torgal, 
José Maria Amado Mendes e Fernando Catroga defendem que a história é uma ciência especial, tratando-se de Literatura (de expressão) científica, ainda que este empreendimento pioneiro, partindo de princípios metodológicos comuns, saia enriquecido das metodologias particulares e dos estilos de cada um dos historiadores responsáveis (TORGAL; MENDES; CATROGA 1996, p. 9).

Sobretudo a partir dos anos 1990, ou talvez dos finais da década anterior, existe uma tendência na história da historiografia portuguesa, em nosso entender minoritária em termos quantitativos, mas muito relevante no plano teórico-metodológico, que poderíamos denominar de História Narrativa. Foi problematizada, de modo pioneiro e decisivo, ainda nos anos 80 por António Manuel Hespanha e tem vindo a ser desenvolvida sobretudo por Maria de Fátima Bonifácio ou, de modo diverso, por Rui Bebiano (HESPANHA 1986, p. 5-83; BONIFÁCIO 1993; 1999a, p. 11-28; BEBIANO 2000a, p. 59-86), mas também por Luís Adão da Fonseca, ainda que este historiador mantenha uma defesa mais clara da História como ciência.

\section{Implicações da história narrativa na narrativa historiográfica: um enquadramento internacional}

A escrita historiográfica pode envolver um esbatimento, sem dissolução de fronteiras, entre a história e a ficção. Esta é maioritariamente entendida pelos historiadores analisados neste trabalho como seleção e reconstrução de dados, transformados em fatos históricos, deixando-se parte considerável da criatividade, da invenção ou da fantasia para a literatura, pelo menos no que tange à vertente mais livre e incondicionada de cada uma dessas dimensões (MOREIRA 2012, p. 17-47).

No imediato, apresentamos um contexto internacional sumário de historiadores que, antes dos cultores de Clio que nos vão ocupar, terão reagido contra os Annales, ou que lhes foram pelo menos paralelos e, eventualmente, indiferentes.

Recusamos o relativismo puro, que tudo reduz à subjetividade dos historiadores, preocupados em perscrutar o carácter lógico e quase sublime dos textos, configuradores de uma realidade que sem eles não existe, como parece transparecer de alguns trabalhos de Frank Ankersmit (ANKERSMIT 1983) ou adquire uma intangível espectralidade traumática (veja-se, para o efeito, alguns estudos de Dominick LaCapra (LACAPRA 1985).

Nos seus momentos mais extremos, como em The Content of the Form (WHITE 1983), ou já antes, talvez menos, na Metahistory (WHITE 1973), também Hayden White defendeu a especificidade linguística do discurso historiográfico, portador de figuras de retórica diferenciadoras, dado que, em última análise, caberia ao historiador não a representação do passado e sim uma reconfiguração imaginativa, devedora, quase em exclusivo, ao cultor de Clio, normalmente alguém provindo das áreas de Literatura das universidades americanas, nas quais a História se reduzia, e continua a limitar-se, a um gênero literário. Convém não esquecer que, desde os anos 1960, nas universidades americanas, o pós-modernismo começou a ter capacidade de penetração e fortuna intelectual, entrando no respectivo meio graças à conjugação de diversos fatores: o mundo 
continuava dividido em dois blocos políticos, a Guerra Fria protagonizada pela URSS e pelos Estados Unidos da América; estes últimos encontravam-se a braços com um profundo conflito bélico no Vietname; e os movimentos de libertação dos negros e de emancipação das mulheres ou das minorias sexuais estavam em efervescência. Todos esses acontecimentos favoreceram a recomposição das elites universitárias e a afirmação de novos temas, erguidos como causas. Todavia, antes deste quadro, no interior do continente europeu, 0 estruturalismo e o pós-estruturalismo receberam notório acolhimento, através da afirmação de autores ligados a uma epistemologia ou filosofia crítica da história. Aliás, ainda antes, o sociólogo Raymond Aron publicara Philosophie de L'Histoire (ARON 1950). Em 1954 foi a vez de ser dado à estampa o estudo de Henri-Irenée Marrou intitulado De la conaissance historique. Em ambos os trabalhos se destaca a defesa da subjetividade historiográfica, que não deixa de se sintonizar com a procura de objetividade.

Nos anos 70 deu-se o Lingusitic Turn que, no âmbito historiográfico, sublinhou a reação ao estruturalismo braudeliano, protagonizada previamente pela maioria dos autores e obras antecitados. Michel Foucault debruçara-se, ainda na década anterior, sobre Les Mots et les Choses e desenvolveu, em 1969, uma Archéologie du Savoir defendendo também a existência do poder mais enquanto relação, sem um centro, do que como um atributo (FOUCAULT 1966; 1969). Roland Barthes concentrou-se no Dicours de l' Histoire (BARTHES 1967) destacando: o enunciado, a enunciação, o enunciador e o destinatário do discurso historiográfico. $\mathrm{O}$ historiador que mais terá seguido Foucault foi Paul Veyne (VEYNE 1971), para o qual a História é apenas uma narrativa de factos verossímeis, abrindo caminho para o pós-modernismo, sobretudo numa das suas vertentes que, em nosso entender, tende a confundir a relatividade do conhecimento histórico, por nós desejada, com um perigoso relativismo infrene.

Na revisão bibliográfica, Maria de Fátima Bonifácio, Rui Bebiano e Luís Adão da Fonseca assimilaram, de modos diversos, o Linguistic Turn e o Pós-Modernismo, entrando em diálogo com autores e obras representativos de ambos, mas pertencendo, em nosso entender, a algo mais vasto e difícil de conter em limites muito estritos ou restritivos.

Maria de Fátima Bonifácio parece mais sensível à História Narrativa tradicional, conjugando-a com algumas ideias de Lawrence Stone, Paul Ricoeur (RICOEUR 1981) e o narrativismo, apontando a teoria dos tropos de White, sem subscrever as concepções deste de modo global. Rui Bebiano analisa a perspectiva nietzschiana, mas relaciona-a com os pontos de vista de Lawrence Stone e as análises ricoeurianas, destacando trabalhos de Georges Duby e Eric Hobsbawm. Por seu turno, Luís Adão da Fonseca segue bastante Krzysztof Pomian, entre outros (FONSECA 2004, p. 275).

\section{A história narrativa portuguesa na actualidade e suas relações com a literatura}

Entre 1971 e 1990, o historiador Keith Thomas (THOMAS 1988) e os estudiosos da literatura Asa Briggs (BRIGGS 1978) e Lionel Gossman escreveram estudos, muito diferentes entre si, sobre as relações entre a história e a literatura, 
sendo que este último pesquisador reuniu, em 1990, ensaios escritos entre 1971 e 1988 (GOSSMAN 1990).

A partir dos anos 1990 do século passado, a prestigiada revista Annales publicou dois números sobre as relações entre as duas áreas referidas. $\mathrm{Na}$ introdução ao primeiro, de 1994, Christian Jouhaud reconhece que os cultores de Clio interessam-se menos no cruzamento dessas temáticas do que os littéraires, clamando por uma história das práticas culturais. Este investigador francês defende uma ampliação e o cruzamento de escalas de análise, e problematiza a alegada transparência da noção de contexto (JOUHAUD 1994, p. 271-276).

Em 2010, Étienne Anheim e Antoine Lilti, na sua apresentação ao número dos Annales intitulado significativamente Savoirs de la littérature, congratulam-se com o facto de os historiadores terem alegadamente aprendido a lição e considerarem o conhecimento científico do passado ilusório (ANHEIM; LILTI 2010, p. 253-260).

Entre essas duas datas, a linguista Régine Robin punha, de algum modo, em causa autonomias entre a história e a literatura, defendendo uma abordagem linguística da história (ROBIN 1995). Num artigo publicado em 2012, o historiador François Hartog pergunta-se sobre o que a literatura fez da história e à história, referindo-se a polêmicas e à recepção do número dos Annales de 2010, anteriormente aludido (HARTOG 2012).

Os estudos de cultores de Clio portugueses foram publicados depois do primeiro número monográfico dos Annales citado e antes do segundo, perfilando retoricamente a possibilidade de jogos de escalas, sem abdicarem de uma 140 concentração prática no seu ponto de partida historiográfico. Pode aplicar-se ao inventário que se segue a questão colocada por Hartog, invertendo-Ihe o sentido, interrogando $O$ que a história faz da literatura e à literatura? A narrativa historiográfica pode ser, em nosso entender, mais bem compreendida se integrada num conspecto mais vasto, incidente sobre o ofício do historiador no campo historiográfico e nas diversas esferas do social. Nesta pesquisa, esse exercício não será sempre possível, projetando-se um trabalho mais aprofundado para ocasiões futuras. Toda a escrita da história envolve uma componente narrativa, tantas vezes multímoda. Contudo, reservamos a expressão História Narrativa para abranger, sob um signo e denominador comuns, de teor discutível, uma parte da historiografia portuguesa, provavelmente minoritária, que se aproxima da abordagem e problematização de dimensões artísticas, indagando formas extremamente controladas de ficção, entendida esta maioritariamente enquanto construção narrativa de acontecimentos, assente num estilo próximo do literário, questionando-se a rigidez que alguns cultores do paradigma neomoderno dominante alegadamente demonstram.

Os estudos efectuados em Portugal sobre as possíveis relações entre a história e a literatura são escassos e por vezes versam a temática de modo indirecto, em função de um dos pólos da equação, surgindo o outro subsidiariamente, como acontece no artigo de Fátima Bonifácio A narrativa na "época pós-histórica", dado à estampa em 1999.

A autora nasceu em Lisboa em 1948. Licenciou-se em 1977, na Faculdade de Letras de Lisboa e, no ano seguinte, tornou-se investigadora do GIS, 
Grupo de Investigações Sociais, fundado e dirigido por Adérito Sedas Nunes. De 1980 até 2006, deu aulas de História na Faculdade de Ciências Sociais e Humanas da Universidade Nova de Lisboa. Em 1981 passou a pertencer ao Instituto de Ciências Sociais. Destacou-se nos Estudos sobre o século XIX Português, aos quais continua a dedicar-se. Concluiu a tese doutoral em 1990, na qual a historiadora se debruçou sobre $A$ via proteccionista do liberalismo português: política e economia nas relações luso-britânicas, 1834-43. Esta tese inscreve-se na história econômica, mas nela já pulsa a história política. A própria historiadora admite, numa entrevista (RIBEIRO 2014), que a sua actividade de historiadora foi sempre norteada pela vontade de canalizar para Clio o gosto pela política. Este espírito e as ideias que contempla presidiram à redacção de $O$ abençoado retorno da velha história, publicado em 1993, não por acaso na Revista Análise Social (e, em nosso entender, influenciado pela historiadora britânica Gertrude Himmelfarb), estudo no qual a historiadora lançara as bases especulativas do tipo de reflexão historiográfica que viria a reiterar alguns anos volvidos.

O artigo A narrativa na era pós-histórica foi publicado ainda em 1999 e voltou a merecer guarida na publicação do Instituto de Ciências Sociais, resultando essencialmente teórico- reflexivo. A historiadora começa por elaborar um diagnóstico sobre a história (como disciplina) no final dos anos 90 do século $\mathrm{XX}$, sintetizando brevemente as perspectivas de José Mattoso, François Furet ou John Elliott (BONIFÁCIO 1999a, p. 11). Enquanto o primeiro se mostra inquieto e perplexo face à variedade e minudência na investigação historiográfica contemporânea, o segundo apelida-a de "vagabundagem", deplorando-a, e o terceiro sublinha uma fragmentação tendencialmente anárquica.

A história na época pós-histórica caracteriza-se, alegadamente, pela inexistência de unidade (temática e de propósitos) e de compartimentações, fronteiras ou hierarquias. No entanto, a história científica, triunfante entre os anos 1950 e 1970, terá preparado este quadro, mas ainda se movia num espectro assente na modernidade historiográfica, promovendo, no entender da historiadora em análise, uma supressão do referencial humano em favor de uma elucidação ou lógica abstracta entre estruturas, radiografando processos objectivos e desmontando a sua lógica interna (BONIFÁCIO 1999a, p. 15).

Maria de Fátima Bonifácio constata que as estruturas braudelianas tinham uma duração, ao contrário da desintegração total presente na actualidade. A historiadora sublinha que o modo dominante de história científica nos anos 1950 a 1970 não terminou nos dias de hoje; sobrevive, mas perdeu o seu estatuto: "A História cientista [...] não acabou. Mas o que sem dúvida acabou foi o privilégio que ela reivindicava [...]" (BONIFÁCIO 1999a, p. 17).

Maria de Fátima Bonifácio prefere claramente a História Narrativa, defendendo que desde os anos 80 até a actualidade na qual escreve concretizou-se, alegadamente, uma fragilização do discurso historiográfico científico, entrando-se naquilo que A. M. Hespanha chama niilismo epistemológico, assente numa proliferação de assuntos, métodos, géneros, escalas, assistindo-se a uma pulverização da verdade, da moral e da consciência do homem. 
A historiadora expõe as descrições do historiador referido, mas também demonstra actualização bibliográfica assinalável, citando as discussões em torno da pós-modernidade historiográfica efectuadas na American Historical Review, entre outros, por John Toewes, Lawrence Levine e David Harlan, todos publicados em 1989, sem esquecer o trabalho de Lawrece Stone, dado à estampa em 1992 na Past and Present, na sequência de uma investigação seminal do mesmo autor, de 1979, intitulada The Revival of Narrative (BONIFÁCIO 1999a, p. 18). Na época pós-histórica concretizou-se a dupla impugnação da história científica e, com ela, do real como objecto de estudo bem como das formas desse estudo ligadas à prova, à verificação, à imparcialidade e aos códigos de inferência contra a arbitrariedade.

A autora aceita a diversidade de formas de conhecimento historiográfico possíveis como inevitabilidade e algo que pode ser positivo, desde que os historiadores procedam a uma autocrítica dos seus processos:

Já noutro lado me alonguei sobre a utilidade explicativa da narrativa histórica, na linha, expressamente citada, dos contributos dados pela filosofia analítica da história nos anos 60 , e, por outro lado, na linha de um entendimento da narrativa bebido em Ricoeur e que a toma pela tradução, ou reflexo, ao nível da linguagem, da temporalidade, como estrutura básica da existência humana. [...] já em 1994 escrevi que entendia a história como um género literário, sujeito [...] a regras determinadas e específicas. Entre elas [...] a de justificar o enredo escolhido (BONIFÁCIO 1999a, p. 20).

Essa citação demonstra que Maria de Fátima Bonifácio silencia de propósito os filósofos analíticos avessos aos narrativismos, como Hempel e as suas covering laws, dado que este e os seus seguidores procuraram, de modos diversos, graus de generalidade para a história próximos da procura de leis alegadamente das ciências naturais. A historiadora em consideração parece adversária dessas inquirições. Por outro lado, salvaguarda e destaca o caráter narrativo da experiência humana, dado que a narrativa organiza a temporalidade - daí a referência a Ricoeur.

Maria de Fátima Bonifácio concretiza, em nosso entender, neste passo, a inserção numa história narrativa, implícita em todo o seu artigo intitulado $A$ narrativa na era pós-histórica, que se assume como género literário, na sua vertente não-ficcional.

No plano da representação, Maria de Fátima Bonifácio rejeita a procura da realidade tal como ela é, preferindo apresentar uma versão plausível de um mundo possível. A historiadora partilha a visão de Oliveira Martins sobre a história no que tange a assumi-la como género literário, portador de uma moral, mas não se coíbe de admitir insuficiências na investigação empírica e na visão teórica concretizadas pelo historiador oitocentista, apontando-lhe possíveis excessos na presença do narrador e defendendo a importância de outras visões sobre o século XIX português (BONIFÁCIO 1999a, p. 25).

Todavia, em nosso entender, a autora, parcialmente por se dedicar aos estudos sobre a época histórica referida, parece admirar uma historiografia 
que reclama uma matriz romântica, com algumas ressonâncias de cunho micheletiano, na qual a vivacidade do relato é fundamental, socorrendo-se de recursos ficcionais, mas sempre apenas ao nível da expressividade literária.

A cultora de Clio termina $A$ narrativa na época pós-histórica, opondo-se ao consumismo dominante na sociedade de massas (BONIFÁCIO 1999a p. 27-28). Torna-se curioso verificar que alguns dos debates patentes em Sur la Crise de l' Histoire encontram aqui profícuo acolhimento, sendo assimilados articuladamente (NOIRIEL 1995).

Do nosso ponto de vista, esta historiadora defende, em diversos estudos e em entrevistas, uma matriz ideológica conservadora não-reacionária, em diálogo com um liberalismo moderado. Todavia, esta mera intuição pode conter perigosa generalização, que exige aprimoramentos críticos futuros.

Por seu turno, Rui Bebiano, no seu artigo intitulado Sobre a História como Poética, publicado em 2000, no número consagrado pela Revista de História das Ideias da Universidade de Coimbra às relações entre a história e a literatura (BEBIANO 2000, p. 59), percorre caminhos bibliográficos alternativos à reflexão sobre o trabalho citado de Noiriel ou os Passés Recomposés, obra dirigida por Jean Boutier e Dominique Julia (BOUTIER; JULIA 1995). Em nosso entender, essa situação talvez se deva ao facto de Bebiano não encarar como crise o momento vivido pela historiografia a partir dos anos 80 do século passado, considerando natural o aparecimento de alternativas à história canónica e que implicaram a fragmentação do campo historiográfico. Segue na linha de Fátima Bonifácio, alinhando pela valorização da narrativa historiográfica como género literário, no qual se registram e organizam eventos, mas manifesta menor inquietação face à questão da renovação da escrita da história (BEBIANO 2000a, p. 60).

Rui Manuel Bebiano Nascimento nasceu em Castanheira de Pera em 1952. Desde cedo, manifestou o gosto pela comunicação, também patente no estudo em análise, escrevendo para o suplemento juvenil do Jornal República e para o quinzenário da sua terra, o Castanheirense. Esta actividade começou um ano depois do Maio de 1968 em Paris, coincidindo com a Crise Estudantil em Coimbra, sobre a qual veio a debruçar-se enquanto historiador algumas décadas volvidas, interessando-se pelas questões do imaginário e das representações dos estudantes. Em 1970, influenciado e marcado por todo este ambiente de contestação e oposição ao Estado Novo, também agiu em conformidade com os ideais oposicionistas que perfilhava, tendo sido detido pela polícia política duas vezes (BEBIANO 2011).

A tese de Doutoramento de Rui Bebiano, defendida em provas públicas a 26 de junho de 1997, foi posteriormente publicada em 2000, no mesmo ano do artigo em vertente análise, sob o título A Pena de Morte, Escrita de Guerra em Portugal e na Europa, séculos XVI- XVIII. Trata-se de um estudo alicerçado em extenso trabalho de arquivo e crítica de documentos, mas debruçando-se sobre a escrita e o discurso no que tange a assuntos militares da Restauração - uma abordagem inovadora (BEBIANO 2000b, p. 13-60). Não admira, portanto, que as questões da escrita e do discurso sejam alvo de uma atenção mais alargada e genérica, essencialmente reflexiva, no artigo Sobre a História como Poética. 
Este trabalho dialoga com Aristóteles desde o título e centra-se no estatuto da escrita da história (ciência ou arte) e na narrativa, enquanto núcleo à volta do qual gravitam as questões da verdade historiográfica e da reconfiguração disciplinar.

Antes de refletir sincronicamente sobre a actualidade, e em defesa da dimensão artística da história, o autor descreve, de forma sumária e acutilante, um percurso de cerca de mais de dois mil anos, sustentando que de Tucídides e Tácito até Gibbon e Michelet, no século XIX, a história sempre conjugou conhecimento, destreza e arte. Foi exactamente no oitocentos que a vocação disciplinar e científica começou a desenvolver-se, materializando uma leitura essencialmente crítica dos documentos, visando o rigor metodológico no apuramento de uma verdade entendida como adequação à realidade dos factos. Embora só tenha triunfado, parcialmente, no século referido, esta aspiração cientificista foi preparada pelo Racionalismo das Luzes (BEBIANO 2000a, p. 59).

Rui Bebiano exime-se a enunciar o Romantismo Crítico, a Escola Prussiana, Ranke e o Rankeanismo, ou a Escola Metódica. Tampouco descreve os Annales de modo detalhado, contornando a problematização das suas várias fases, ou a eventual especificação das respectivas contradições internas. O historiador também não explica as razões que o conduziram à consideração dos anos 80 do século XX. Interessa-lhe, em nosso entender, sublinhar que terá sido efectuada mais fortemente nessa década a crítica da história objectiva e a reaproximação às artes. Todavia, esse processo esteve longe de ser linear ou dicotómico, não se cingindo a uma substituição incontroversa de paradigmas. Rui Bebiano reconhece implicitamente as dificuldades, os avanços, recuos e paralelismos verificados, afirmando a parcial manutenção de focos relevantes e activos da história cientista ou cientificista (BEBIANO 2000a, p. 60).

Aliás, a prática historiográfica do historiador, vertida mormente nas suas teses e noutros estudos, preserva, do nosso ponto de vista, uma vertente estruturada e criticamente empírica, tendo em conta a procura de verdades relativas ou aproximadas, incentivando, paralelamente, uma abertura e adesão teórica a outras metodologias e formas de escrita.

Rui Bebiano convoca, implicitamente, a Poética de Aristóteles, que Fátima Bonifácio aflorara de modo breve. Ambos os cultores de Clio seguem o estagirita no que tange à consideração da história e da poesia. Todavia, para Aristóteles, a primeira possui um estatuto inferior, dado que narra o que aconteceu, enquanto a segunda se debruça sobre o que poderia ter acontecido, permitindo-se um exercício mais livre da imaginação. Os dois historiadores portugueses referidos divergem deste postulado na parte que consagra a fidelidade absoluta e mimética da história ao acontecido, defendendo que nem sequer a respetiva narração é cabal. De resto, ambos sustentam que a história deve se aproximar da expressividade ficcional da poesia, assumindo-se como Poética. Nessa tarefa, Rui Bebiano, sobretudo no artigo em consideração, materializa, mais claramente, a intenção de incorporar esta dimensão no trabalho historiográfico, eventualmente ao arrepio de correntes narratológicas. Defende, no dealbar do seu texto, de modo inequívoco, a abordagem pós-moderna, embora, progressivamente, apresente alternativas. 
Rui Bebiano diagnostica brevemente a situação da historiografia, descrevendo a crescente possibilidade de abertura dos saberes ligados a Clio a um diálogo com outros âmbitos de estudos. Esta permeabilidade comporta, do lado dos historiadores, a proximidade com a literatura, ou com a crítica literária. Encontra-se, assim, devidamente enquadrada a análise sumária das perspectivas intelectuais de Hayden White (1973), Dominick LaCapra (1985), Paul Veyne (1971) ou Lawrence Stone (1979, p. 3-24).

O autor de Sobre a História como poética começa por citar a Metahistory de 1973 e nota a aproximação promovida por White entre factos e ficção, insistindo na inextrincável ligação entre narrativa e imaginação, contribuindo ambas para a reconstrução do passado através da ativação de um imaginário poético. Rui Bebiano enfatiza a propensão do intelectual americano para destacar as similitudes metafóricas e as estruturas convencionais das ficções, considerando a criação historiográfica uma operação literária produtora de ficção, recorrendo a discursos figurativos para a enunciação de dados a analisar.

No seguimento destas considerações, o autor de Sobre a História como poética debruça-se sobre o posicionamento de LaCapra face a White. Os dois pensadores americanos valorizam a dimensão literária da experiência social, a estrutura literária da escrita historiográfica e o pensamento abstrato. LaCapra confere enorme relevância ao conhecimento dos textos, devido à sua natureza informativa, à influência da e sobre a linguagem dos estudiosos, que, por seu turno, reconstroem o real vivido, assomando o contexto histórico no e do texto historiográfico, propiciando e incentivando a confusão entre as duas instâncias.

Rui Bebiano analisa, então, a posição de Paul Veyne. Resulta implícito que o historiador francês radicaliza os pressupostos, as reflexões teóricas e as práticas historiográficas descritas, considerando a história uma narrativa de factos verosímeis, lacunar a nível disciplinar, tendo que recorrer a estratagemas para elidir fraquezas. Os documentos e os testemunhos são encarados como parciais, dado que os eventos também não são apreendidos de forma direta e completa, mas reconstruídos de modo imperfeito e lateral (BEBIANO 2000a, p. 70).

Por seu turno, Lawrence Stone, também citado pelo cultor de Clio em análise, comparece em 1979, através do artigo "The Revival of Narrative", como crítico da história-ciência, à qual também se devotara. Visa a concepção cientista em três eixos, prodigalizados nos anos 50-60: o modelo marxista (que esteve na base da revista Past and Present, da qual Stone foi director); o quantitativismo de uma parte dos Annales e a Cliometria norte-americana (BEBIANO 2000a, p. 71). Segundo o historiador britânico, até a história dita mais científica inclui, a contrapelo, recursos e estratégias de teor narrativo. Na perspetiva de Rui Bebiano, Stone privilegia a História Narrativa, sem, contudo, diluí-la na literatura, ao contrário do exercício no sentido da dissolução, permitido e parcialmente incentivado pela alegada iconoclastia de Paul Veyne.

Rui Bebiano apoia-se nas posições de José Mattoso sobre a escrita da história, ressaltando a relevância que este confere à qualidade formal, à escolha de dados e sua reconstrução interpretativa e à carga poética global. A história deve conciliar, no entender de José Mattoso, o rigor metodológico e a qualidade 
artística, não sacrificando nenhum dos vectores. Paul Ricoeur foi fundamental nessa mesma linha, que Rui Bebiano também defende de modo cada vez mais claro no seu artigo. No início deste pontificara Nietzsche, mas percebe-se agora que pode ter sido convocado menos em função do seu niilismo ou relativismo, mas para que dele se aproveitasse o perspectivismo e uma relatividade na consideração da verdade histórica (BEBIANO 2000a, p. 81).

Rui Bebiano cita dois exemplos de historiadores que conjugaram o rigor e um estilo bem conseguido: Georges Duby, na sua obra Guilherme o marechal e Eric Hobsbawm, na Era dos extremos (BEBIANO 2000a, p. 84). Aliás, em nosso entender, em Sobre a História como poética o seu autor tematiza a ficção enquanto forma de construção da narrativa, da intriga e do enredo, e enquanto recurso indispensável à divulgação de conhecimentos que continuam a ser científicos, sendo, todavia, permeáveis a algumas configurações pós-modernas no plano teórico.

Falta abordar Luís Adão da Fonseca. Num colóquio realizado na Faculdade de Letras do Porto, cujas actas foram dadas à estampa em 2004, com o título Literatura e História, Luís Adão da Fonseca debruçou-se sobre as Relações entre a História e a Literatura no contexto da actual crise da dimensão social na narrativa historiográfica. Trata-se, desde logo, de um artigo que não elide a palavra crise e que parece partilhar, eventual e parcialmente, do afastamento face aos Annales, defendido por Maria de Fátima Bonifácio. Aliás, no percurso biográfico deste historiador avulta, igualmente, uma maior quantidade de trabalhos historiográficos de natureza empírica, voltados para a crítica de fontes.

Luís Adão da Fonseca nasceu em 1945. Licenciou-se na Faculdade de Letras do Porto e concluiu o Doutoramento em Navarra, um ano depois da Revolução de 25 de Abril de 1974 (FONSECA 1975). O cultor de Clio especializou-se em matérias da Nova História Política e da Nova História Militar.

Este historiador aborda o problema da multiplicidade de correntes historiográficas, escolhendo a derradeira década do século XX como posto principal de observação. Analisa, em seguida, as 18 propostas do Manifesto História a Debate (2003), que parte de Santiago de Compostela e envolve historiadores de todo o mundo. Um dos artigos do clausulado postula a necessidade de interdisciplinaridade para fazer face à dispersão e pulverização historiográficas notadas (FONSECA 2004, p. 267). Todavia, esta atitude científica pode ser interna e externa à história, comportando três perigos, no entender do medievalista em questão: a impossibilidade de uma ciência social unificada; transformar o diálogo necessário entre a história e as ciências sociais numa receita mágica; e diluir a história num outro âmbito disciplinar, nomeadamente na Literatura (FONSECA 2004, p. 267).

$\mathrm{Na}$ investigação em análise, Luís Adão da Fonseca reconhece a narrativa como um dos três principais vectores não só da referida interdisciplinaridade, mas também do estatuto da história nela implicado, não se cingindo este a uma componente teórica, mas comportando, igualmente, uma vertente prática, ligada a canais não historiográficos envolvidos na construção da memória social do passado. Nesse universo cada vez mais avassalador, face a esta 
heterogeneidade, que se pode traduzir em complementaridade, mas também em concorrência, agudizando a crise, o historiador se pergunta se ainda há espaço para a história como disciplina científica, ou se apenas pode assumir-se enquanto consciência historiográfica. Apesar das dificuldades e dos obstáculos, Luís Adão da Fonseca parece construir uma argumentação defensora da viabilidade da primeira hipótese esboçada, indagando a posição da consciência num quadro desses, colocando a possibilidade de privilégio e a de igualdade de circunstâncias (FONSECA 2004, p. 268).

Esse jogo de forças e de (des)equilíbrios ocorre com particular acuidade desde a última década do século XX, em relação à qual o medievalista diagnosticou uma alteração de paradigma, que trouxe uma proliferação de mudanças e transformações, abalando decisivamente o paradigma que defendia a verdade desde os gregos, ou a certeza a partir da modernidade, com Descartes ou Bacon, assente em vários pilares: rigor na selecção, organização e classificação dos dados, sem esquecer a racionalidade na fundamentação da argumentação, pesquisando o fundamento subjacente aos respectivos juízos. A procura da certeza podia e pode concitar metodologias de manipulação da realidade pelo sujeito cognoscente (FONSECA 2004, p. 268).

Para Luís Adão da Fonseca, o paradigma estruturado a partir dos pressupostos enunciados foi modificado, mas não destruído, revelando-se, todavia, a seu ver, insuficiente. O cultor de Clio move-se no interior do paradigma da cientificidade, exigindo e procurando a adaptação à explosão de paradigmas e à fragilidade daí decorrente, de modo a perseguir uma verdade relativa. O historiador apoia-se em artigos saídos na American Historical Review, acolhendo uma vertente de reflexão anglo-saxônica, preocupada com a moral ou a ética, tal como fizera a autora de Narrativa na "época pós-histórica". Luís Adão da Fonseca consubstancia uma referência mais alargada a Bernard Baylin e subscreve as diretrizes básicas do editorial de 1981, no qual o historiador norte-americano propusera a configuração da história como uma ciência moral, testando as possibilidades, os limites e as aporias de tal asserção e das realidades que Ihe correspondam. O cultor de Clio português acompanha e assimila esta argumentação, considerando igualmente que, para contrariar a crise, a historiografia contemporânea ganhará em apresentar-se enquanto escrita de narrativas. Aliás, resulta implícito que, tal como Bailyn, também Luís Adão da Fonseca não terá ficado muito convencido com as três temporalidades de Braudel, ou com o powerful framework of coherence, experimentado pelo Marxismo, concretizando o medievista uma via pessoal de possível resposta ao quadro esboçado, alicerçada na seguinte intuição:

É interessante, a meu ver, que o mesmo Bailyn [...] cite expressamente dois autores. Lord Acton e Oscar Handlin. Acontece que o primeiro é um representante da visão liberal da história, e o segundo é o autor da conhecida obra sobre a Verdade na História.

Ou seja, a ligação destas quatro vertentes (narrativa articuladora das diferentes áreas - valor da liberdade - visão liberal - verdade) pode ser um bom ponto de partida para enquadrar o problema da relação História / Liberdade, núcleo central do que procuro explicitar sobre a 
imprescindibilidade da narrativa como núcleo duro do que deve ser a especificidade da consciência historiográfica no conjunto da memória histórica dos tempos actuais (FONSECA, 2004, p. 270).

Segundo a proposta de Luís Adão da Fonseca, a narrativa é o eixo central da consciência historiográfica e um garante da sua viabilidade, assente numa visão liberal, perante a profusão de perspectivas provenientes da memória social mais alargada.

O historiador português defende e promove a aproximação e relação entre a realidade histórica e o discurso historiográfico, criticando o carácter omnívoro da concentração exclusiva neste último, colocando igualmente em causa uma atitude semelhante no que tange ao primeiro. Luís Adão da Fonseca defende a responsabilidade social dos historiadores, mas adverte para as dificuldades de uma exclusividade conferida a esse tipo de abordagem, que, no limite, pode implicar não apenas a desmontagem e análise crítica e devidamente contextualizada de interesses antagónicos, mas também a tomada de partido subjectiva e desafiadora da procura da imparcialidade, indispensável à materialização de decisões conjuntas. O autor apresenta um entendimento que não se esgota na função social dos historiadores, estendendo-se aos usos da verdade historiográfica, conciliando a existência da experiência social e profissional dos cultores de Clio com as suas escritas, concretizando uma análise social da narrativa historiográfica (FONSECA 2004, p. 274).

O historiador não pretende elaborar qualquer teoria da narrativa 148 historiográfica, uma vez que reconhece e vastidão da bibliografia disponível a esse nível. Apenas procura testar aquilo que defende, ou seja, o peso e o poder do reforço da produção da narrativa historiográfica na luta pelo reenquadramento do respectivo consumo social, contribuindo este para fazer face ao desgaste sofrido pelas formas historiográficas científicas na memória colectiva, em consequência do embate com a memória social ligada aos atropelos alegadamente perpetrados pela sociedade de consumo e pelos meios de comunicação de massas colocados ao seu dispor. As revindicações retóricas e práticas de herança e património comuns esbarram no desinteresse e na amnésia dos públicos massificados, paradoxalmente dotados de uma maior e mais rápida possibilidade de acesso à informação, mas que não a retêm ou assimilam em muitos casos, pelo menos no que respeita à história.

Para Luís Adão da Fonseca a narrativa historiográfica só conseguirá juntar o cumprimento da sua responsabilidade ao sucesso perante o público, seguindo o exemplo, ao nível de consumo, do romance histórico, enquanto género bem sucedido, se lograr conciliar a erudição com uma forma e um estilo literários na apresentação da narrativa.

\section{Afloramento da questão da historicidade e considerações finais}

Nesta investigação, procuramos perceber o modo como Maria de Fátima Bonifácio, Rui Bebiano e Luís Adão da Fonseca perspectivam a História Narrativa, situando-se no seu interior, sendo de salientar que o último historiador referido 
confere maior peso à história científica do que os anteriores, embora nenhum estudioso a desrespeite ou defenda a sua liminar destruição.

No que se refere ao estatuto da história enquanto historiografia, em face do exposto, parece evidente que predomina a sua consideração alicerçada na relatividade ou até no relativismo das verdades e realidades históricas, prevalecendo a imaginação controlada na edificação de uma ficção entendida como selecção e construção de acontecimentos. Para o senso comum, a historicidade parece implicar essencialmente o que acontece entre dois lapsos cronológicos, na vida dos indivíduos ou das sociedades, coincidindo com o que é histórico. Num plano especializado, François Hartog reflecte sobre os regimes de historicidade, mas neste estudo não afloramos sequer esta complexa temática (HARTOG 2013).

Para os historiadores analisados, a visão estritamente estática e descritiva da historicidade parece subalterna e instrumental, preferindo encará-la quase sempre de modo implícito, enquanto forma activa e dinâmica como os indivíduos ou os historiadores se relacionam, no seu presente, com essa atualidade, construindo narrativas sobre o passado, conhecido de forma imperfeita, e o futuro.

A historicidade pode, por isso, envolver a escrita historiográfica como sua expressão, num duplo sentido, cronológico e ontológico (ARAÚJO 2013, p. 34-44). Os cultores de Clio analisados, sobretudo os dois primeiros, utilizam maioritariamente aquele em função deste. Se a historicidade congrega uma dimensão ontológica (ARAúJO 2013, p 34-44), esta procura as virtualidades da escrita historiográfica, sobretudo a riqueza literária no plano estilístico, enfatizada por Luís Adão da Fonseca, para tentar veicular princípios e valores próprios da história enquanto narrativa e, também, por maioria de razão, da História Narrativa. Fátima Bonifácio enfatiza a componente ética da função do historiador, associando-a à fruição estética e à divulgação, por esta ordem. Rui Bebiano respeita e segue este itinerário, mas acrescenta-lhe as especificidades de uma perspectiva comunicacional e retórica, transversal a todos os domínios enunciados. Luís Adão da Fonseca enfatiza estas duas últimas perspectivas como substrato das restantes.

Em nosso entender, a divulgação e o estilo como tônica parecem ser os principais elementos comuns presentes na História Narrativa patenteada nos artigos estudados.

Daí que a relação de todos esses historiadores com a literatura pareça sempre subsidiária do tratamento de questões historiográficas, permanecendo muito no interior destas. Talvez se possam divisar posições de compromisso entre o historicismo e o narrativismo, consubstanciando este último de modo moderado, avesso a cientismos, mas conservando a procura da cientificidade. Perfilhamos a história social das narrativas, conforme a entende Luís Adão da Fonseca, e consideramos ser possível uma história cultural do literário, olhando historiograficamente as coordenadas deste. Entendemos que o afloramento da história literária é um caminho a explorar, a partir dos modelos historiográficos, conciliando autores, obras, coordenadas espaciotemporais, personalidades como personagens, géneros e períodos literários. 
A história literária pode ser mais filológica, como entendem alguns (FRAISSE 2001, p. 6-19), comportando a assimilação de dados estatísticos (MYLNE 1987, p. 15), ou, então, conciliando a vertente filológica com a estética da recepção e uma dimensão teórico-conceptual acentuada, como perfilham outros (PERKINS 1993, p. 1-27). O diálogo destas e de outras perspectivas é profícuo e o historiador não deve ignorá-lo.

\section{Referências bibliográficas}

ANHEIM, Étienne; LILTI, Antoine. Savoirs de la litérature. Annales: Histoire, Sciences Sociales, n. 2, 2010, p. 253-260.

ANKERSMIT, Frank. Narrative logic: a semantic analysis of historian language. Haia: Martinus Nijkoff Philosophy Library, 1983.

ARON, Raymond. La philosophie de I'histoire: essai sur une théorie allemande de I'histoire. 2. a edição Paris: Vrin, 1950.

BARTHES, Roland. Le Discours de I'histoire. Social Science Information, v. 6, p. 63-75, 1967.

BEBIANO, Rui. Sobre a História como poética. Revista de História e Teoria das Ideias, v. 21, p. 59-86, 2000a.

A Pena de Marte: escrita de guerra em Portugal e na Europa (séculos XVI- XVIII). Coimbra: Minerva, 2000b.

Rui Bebiano. Coimbra: Centro de Estudos Sociais Laboratório Associado da Universidade de Coimbra, 2011. Disponível em. http:// http://www. ces.uc.pt/investigadores/cv/rui_bebiano.php. Acesso em 10 jul. 2014.

BONIFÁCIO, Maria de Fátima. O abençoado retorno da velha história. Análise Social, v. 28, n. 122, p. 623-630, 1993.

A narrativa na época pós-histórica. Análise Social, v. 34, n. 150, p. 11-28, 1999a.

Apologia da História Política. Lisboa: Quetzal, 1999b.

BRIGGS, Asa. History and Literature. Gloucestershire: Cheltenham College, 1978.

BOUTIER, Jean; JULIA Dominique (orgs.). Passés Recomposés: champs et chantiers de I' histoire. Paris: Autrement, 1995.

CATROGA, Fernando. Os Passos do Homem como Restolho do Tempo: Memória e Fim do Fim da História. Coimbra: Almedina, 2009.

FONSECA, Luís Adão da, As Relações entre a história e a literatura no contexto da actual crise da narrativa historiográfica. In: COLÓQUIO INTERNACIONAL LITERATURA E HISTÓRIA, 2003, Porto. Actas... Porto, Faculdade de Letras, 2004.

FRAISSE, Luc (org.). L' Histoire Littéraire: ses méthodes et ses résultats Mélanges offerts à Madeleine Bertaud. Paris: Droz, 2001. 
GODINHO, Vitorino Magalhães. A Crise da História e as suas novas directrizes. Lisboa: Empresa Contemporânea de Edições, 1946.

Ensaios III: sobre Teoria da História e Historiografia. Lisboa: Sá da Costa, 1971.

GOSSMAN, Lionel. Between History and Literature. Massachusets: Harvard University Press, 1990.

FOUCAULT, Michel, Les Mots et les Choses: une archéology des sciences humaines. Paris: Gallimard, 1966.

. L'Arquéologie du Savoir. Paris: Gallimard, 1969.

GODINHO, Vitorino Magalhães. Ensaios III: Sobre Teoria da História e Historiografia. Lisboa: Sá da Costa, 1971.

HARTOG, François. Ce que la littérature fait de I'histoire et à I'histoire. In: COLLOQUE LITTÉRATURE ET HISTOIRE EN DÉBATS. Paris: 2012, p. 1-11.

Regimes de Historicidade: Presentismo e experiências do tempo.

Rio de Janeiro: Autêntica, 3a edição 2013.

HESPANHA, António Manuel. "História e sistema: interrogação à historiografia pós- moderna". Ler História, v. 9, p. 65-83, 1986.

HOMEM, Armando Luís de Carvalho. In Memoriam A. H. de Oliveira Marques. 2. A. H. de Oliveira Marques: homenagem. Revista da Faculdade de Letras [UP]. História, III série, v. 9, p. 393-398, 2008.

JOUHAUD, Christian. Présentation. Annales: Histoire, Sciences Sociales, vol. 49, n. 2, p. 271-276, 1994.

LACAPRA, Dominck. History and Criticism. Nova Iorque: Cornell University Press, 1985.

MARQUES, A.H. de Oliveira. Antologia da Historiografia Portuguesa, 2 vols, Lisboa: Publicações Europa-América, 1974.

MATTOSO, José. A escrita da História. Lisboa: Círculo de Leitores, 2002.

MOREIRA, Nuno Bessa. A Revista de História (1912-1928): uma proposta de análise histórico-historiográfica Tese (Doutoramento em História), 2 vols., Porto: Faculdade de Letras da Universidade do Porto, 2012.

MYLNE, Vivienne. Is Literary History Possible? Bristol: School of Modern Languages University of Bristol, 1987.

NOIRIEL, Gérard. Sur la crise de I'histoire. Paris: Belin, 1996.

NUNES, João Paulo Avelãs. O Estado, a Historiografia e Outras Ciências/ Tecnologias sociais. In: As Historiografias Portuguesa e Brasileira no século XX: Olhares Cruzados, João Paulo Avelãs Nunes e Américo Freire (coordenação). Coimbra; Rio de Janeiro: Imprensa da Universidade de Coimbra; Fundação Getúlio Vargas, p. 5379, 2013. 
PERKINS, David. Is Literary History Possible? Baltimore: The Johns Hopkins University Press, 1992.

PESAVENTO, Sandra Jatahy. Fronteiras da Ficção: Diálogos da história com a literatura. Revista de História das Ideias, v. 21, pp. 33-55, 2000.

RIBEIRO, Anabela Mota. Maria de Fátima Bonifácio. Disponível em: http:// http://anabelamotaribeiro.pt/maria-de-fatima-bonifacio-86534. Acesso em: 10 jul. 2014.

RICOEUR, Paul. Temps et Récit. 3 tomos, Paris: Éditions du Seuil, 1983-1985.

ROBIN, Régine. L'Histoire saisie, dessaisie par la littérature? EspacesTemps, n. 59-61, 1995, p. 56-65.

SANTOS, Nádia Maria Weber. Apresentação do Dossiê: "Sandra Jathay Pesavento: A historiadora e suas interlocuções". Revista Fénix, v. 6, n. 2, 2009. Disponível em: http://www.revistafenix.pro.br/PDF19/Apresentacao_do_ Dossie_Nadia_Maria_Weber_Santos.pdf. Acesso em: 10 jul. 2014.

STONE, Lawrence. The revival of narrative: Reflections on a New Old History. Past and Present, n. 85, 1979, p. 3-24.

THOMAS, Keith. History and Literature. Swansea: University College of Swansea, 1988.

TORGAL, Luís Reis; MENDES, José Maria Amado; CATROGA, Fernando (orgs.). 152 História da História em Portugal: séculos XIX-XX. Lisboa: Círculo de Leitores, 1996.

VEYNE, Paul. Comment ont écrit I’histoire: Essai d'epistémologie. Paris: Éditions du Seuil, 1971.

WHITE, Hayden. Metahistory: the Historical Imagination in Nineteenth-Century Europe. The Johns Hopkins University Press, 1973.

Content of the form narrative discourse and historical representation. Baltimore Maryland: The Johns Hopkins University Press, 1983. 